\title{
HIGH CURRENT HIGH ACCURACY IGBT PULSE GENERATOR*
}

\author{
V. V. Nesterov and A. R. Donaldson \\ Stanford Linear Accelerator Center, Stanford University, Stanford, CA 94309 USA
}

A solid state pulse generator capable of delivering high current triangular or trapezoidal pulses into an inductive load has been developed at SLAC. Energy stored in a capacitor bank of the pulse generator is switched to the load through a pair of insulated gate bipolar transistors (IGBT). The circuit can then recover the remaining energy and transfer it back to the capacitor bank without reversing the capacitor voltage. A third IGBT device is employed to control the initial charge to the capacitor bank, a command charging technique, and to compensate for pulse to pulse power losses. The rack mounted pulse generator contains a $525 \mu \mathrm{F}$ capacitor bank. It can deliver $500 \mathrm{~A}$ at $900 \mathrm{~V}$ into inductive loads up to $3 \mathrm{mH}$. The current amplitude and discharge time are controlled to $0.02 \%$ accuracy by a precision controller through the SLAC central computer system. This pulse generator drives a series pair of extraction dipoles.

\section{INTRODUCTION}

A "flat top" pulse generator energizes a bending magnet to extract particle beams from the linear accelerator for the PEP II injector [1]. The IGBT Pulse Generator described in this article, and earlier ones based on Darlington transistors, are used at SLAC in applications where relatively low voltage, low current and slow extraction kickers are required [2]. Major features of these pulse generators are their simple topology, compactness and reliability.

\section{BASIC CIRCUIT DESCRIPTION}

Figure 1 shows a simplified schematic of the pulse generator. Initially the storage capacitor $C$ is charged up to the power supply output voltage. To initiate the discharge of capacitor $C$ into the magnet $\mathrm{L}$, both transistors $\mathrm{Q} 1$ and Q2 are simultaneously turned on. The feedback loop current is constantly monitored and compared to the desired "flat top" reference value. When the current reaches the specified level, which could be up to $500 \mathrm{~A}$, one of the IGBT switches, for example Q1, is turned off. The current still present in the magnet $\mathrm{L}$ will continue to flow through the magnet, but by using a different path: freewheeling through the diode $\mathrm{D} 1$ and conducting transistor $\mathrm{Q} 2$, thus creating a "flat top" on the current pulse.

This "flat top" current will decay exponentially until, at the predetermined time, the second transistor $\mathrm{Q} 2$ is turned off and the remaining magnet current is redirected into the capacitor bank $C$ through the diodes $D 1$ and $D 2$, so that the voltage across the capacitor $C$ never changes in polarity. After the command charging transistor $\mathrm{Q} 3$ is turned on, the $d c$ power source recharges the capacitor $C$ back to its original voltage, making up for any energy losses that occur during the discharge cycle. To increase the flatness of the initial portion of the "flat top" the first IGBT Q1 is turned off slowly by using a rather high value resistor in series with the gate. The drive resistor also minimizes the switching transient voltage at turn-off. A consequence of this slow turn-off is higher power dissipation within the device, but since the unit operates at only $120 \mathrm{~Hz}$ this does not present a problem.

Figure 2 shows the waveforms for various parts of the circuit.

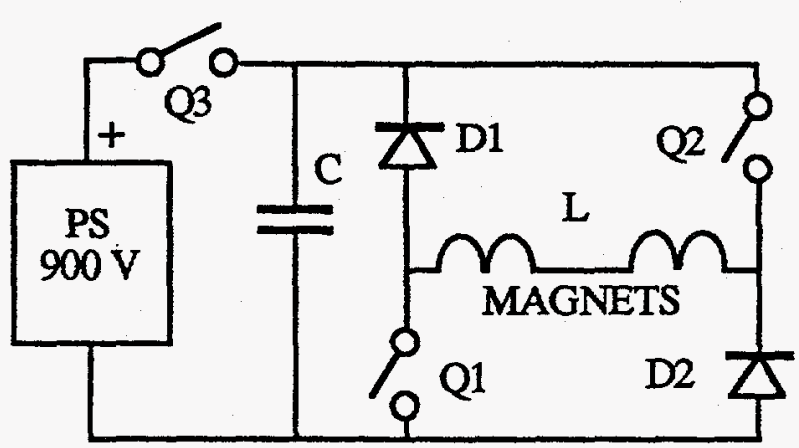

Figure 1. Block diagram of the pulse generator.

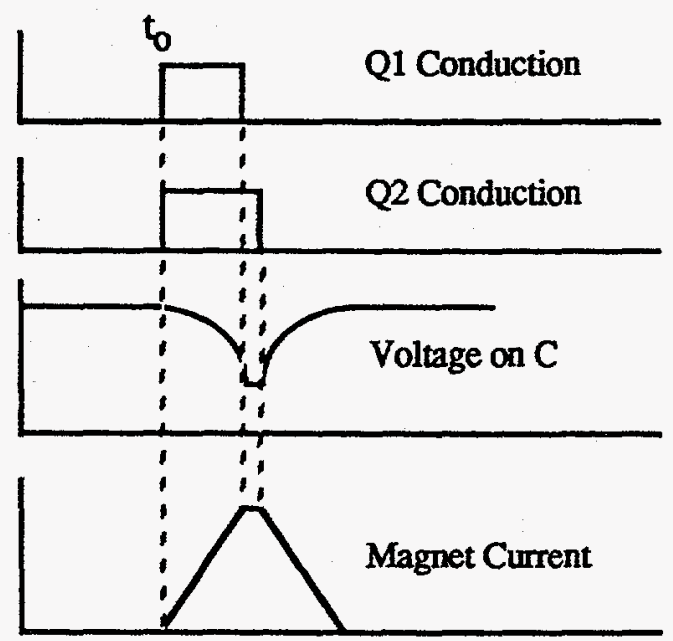

Figure 2. Waveforms for the pulse generator circuit.

"Work supported by the Department of Energy contract DE-AC03-76SF00515 


\section{CONTROL CIRCUIT}

A block diagram of the control circuitry for the IGBT pulse generator is shown in Figure 3. A "NIM" input signal is converted to a CMOS pulse, that activates Timer 1 . The output of this timer controls the beginning and the duration of the $\mathrm{Q} 1$ and $\mathrm{Q} 2$ conducting periods, and limits the maximum rise time of the pulse generator discharge current. As was mentioned above, IGBT Q1 is feedback coupled, and when the feedback signal at the input of the precision comparator reaches the reference level, the output of the "AND" gate will change state, and turn off Q1.

Timer 2 triggered by the input pulse, isolates the dc charging supply from the pulse generator for the load pulse duration. Timer 3 limits the trigger rate to a safe range of repetition rates and protects it from misfiring. The peak detector provides a dc voltage read back scaled to the load current pulse amplitude. It self-resets at the initiation of each current transductor pulse. If triggering pulses disappear for a period longer than the one second time out of Timer 4, this timer will reset the peak detector to zero.

This circuit is contained in a separate chassis that is mounted above the pulse power chassis.

\section{DESIGN CONSIDERATIONS}

The components for the pulse generator are contained in a single rack mounted chassis with the following dimensions: $19^{\prime \prime}$ wide, $10.5^{\prime \prime}$ high and $20^{\prime \prime}$ deep. The $525 \mu \mathrm{F}$.capacitor bank is composed of $15,35 \mu \mathrm{F}, 660 \mathrm{VAC}$

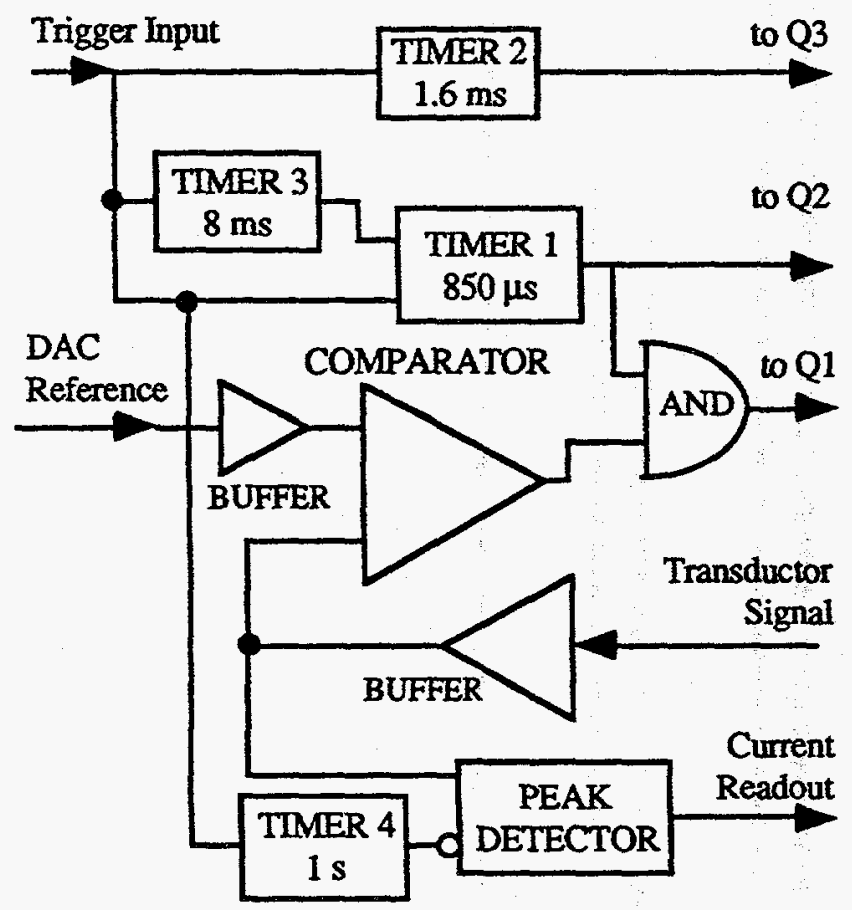

Figure 3. Block diagram of pulse generator controls. parallel capacitors. These units are manufactured by GE.

Powerex $600 \mathrm{~A}, 1200 \mathrm{~V}$ IGBT's are used as the Q1 and $\mathrm{Q} 2$ switches in conjunction with Semikron drivers. Semikron drivers were selected because they have high voltage rating for input to output isolation, they need only one $+15 \mathrm{~V}$ dc source at the grounded side of the control circuit, and their ability to drive IGBT's directly.

Two IGBT and two diode modules are mounted on a common water cooled heat sink. Particular attention has been given to the mechanical layout of the generator chassis to reduce the influence of all parasitic parameters and in effect minimize switching transients. Snubber networks are used across the IGBT's to protect them against transient over voltages. An SCR protection crowbar, as an option, can also be installed at the pulse generator output.

The photo below shows the top of the water cooled heat sink with one IGBT and one diode module visible. The other pair is mounted on the bottom of the heat sink along with the charge control IGBT Q3. The photo only displays three of the 15 capacitors in the bank.

The water hoses for the heat sink are terminated on the back panel of the chassis with quick disconnect fittings.

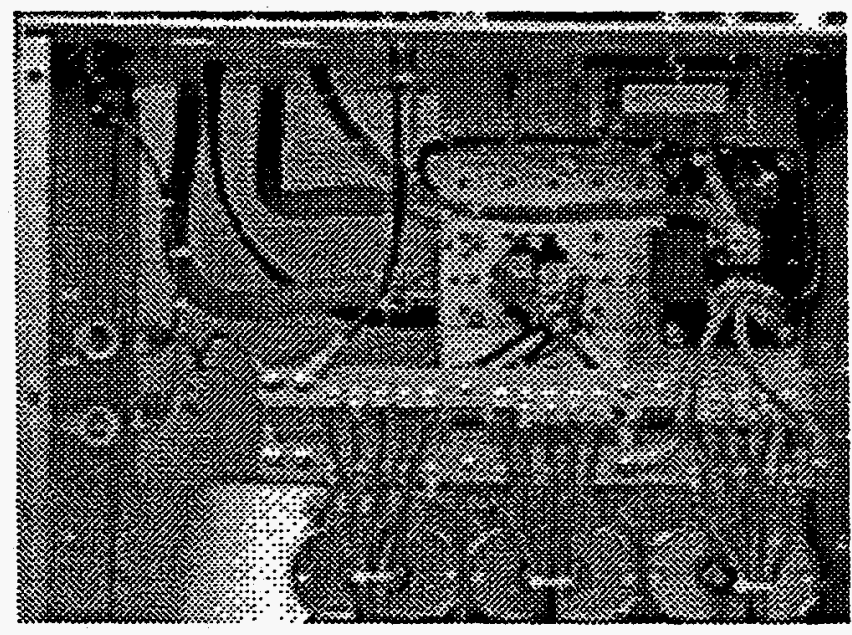

Figure 4: Mechanical layout of pulse power chassis.

A Danfysik $500 \mathrm{~A}$ dc transductor is used in the current feedback loop, as the pulse current sensor. The unit is an integrated zero flux transductor. The measuring head and the electronic cincuit for control and feedback are enclosed one compact package. These units have been temperature cycled over $40^{\circ} \mathrm{C}$ ranges and exhibit stability and accuracy of better than $0.01 \%$. The unit has a small signal band width of $100 \mathrm{kHz}$ that is very adequate for this application.

The initial energy for the capacitor bank and the pulse to pulse make up energy are provided by a $900 \mathrm{~V}, 8 \mathrm{~kJ} / \mathrm{s}$ capacitor charging supply. This power supply will operate up to a maximum voltage of $850 \mathrm{~V}$. It is manufactured by Electronic Measurements, Inc. 


\section{DISCLAIMER}

Portions of this document may be illegible in electronic image products. Images are produced from the best available original document. 


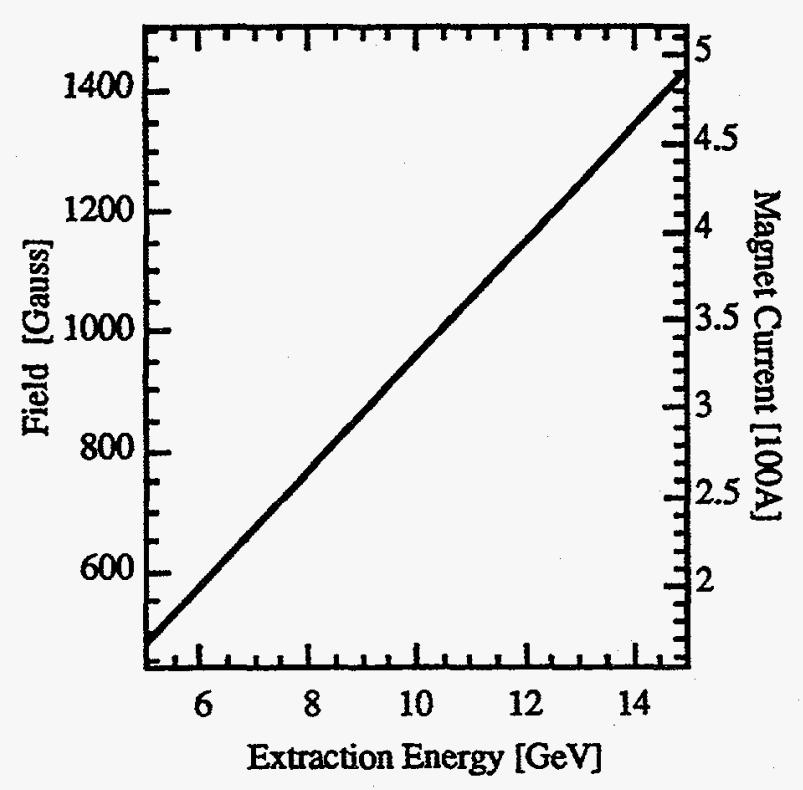

Figure 5. Magnet current vs. extraction energy.

\section{CONCLUSIONS}

The generator has been tested into an inductive load of $1.6 \mathrm{mH}$ (the actual magnet pair) and was delivering current pulses up to $470 \mathrm{~A}$ with a $100 \mu$ s flat top. The pulse to pulse stability at the flat top is equal to or better than $0.02 \%$.

The energy range for extracted beam will be from 8 to $10 \mathrm{GeV}$ [2]. The generator has been tested with the intent to operate up to $12 \mathrm{GeV}$.

The operating range for extraction energy, magnet field and current is shown in Figure 4.

The actual magnet current waveform with a $100 \mu \mathrm{s}$ "flat top" at $470 \mathrm{~A}$, somewhat in excess of that needed for $12 \mathrm{GeV}$, is shown in Figure 5.

The "flat top" was established at $100 \mu \mathrm{s}$ which minimizes any pulser turn-on jitter that would be deleterious to constant energy extraction. The generator can produce much wider "flat top" times, but at the consequence of some droop. We have developed techniques to eliminate the droop, but in this application only a $100 \mu \mathrm{s}$ "flat top" or less is needed for the very short beam pulses being extracted. The current pulse looks somewhat triangular as a result of the narrow "top," but it is very clean and does not exhibit any overshoot or ripple.

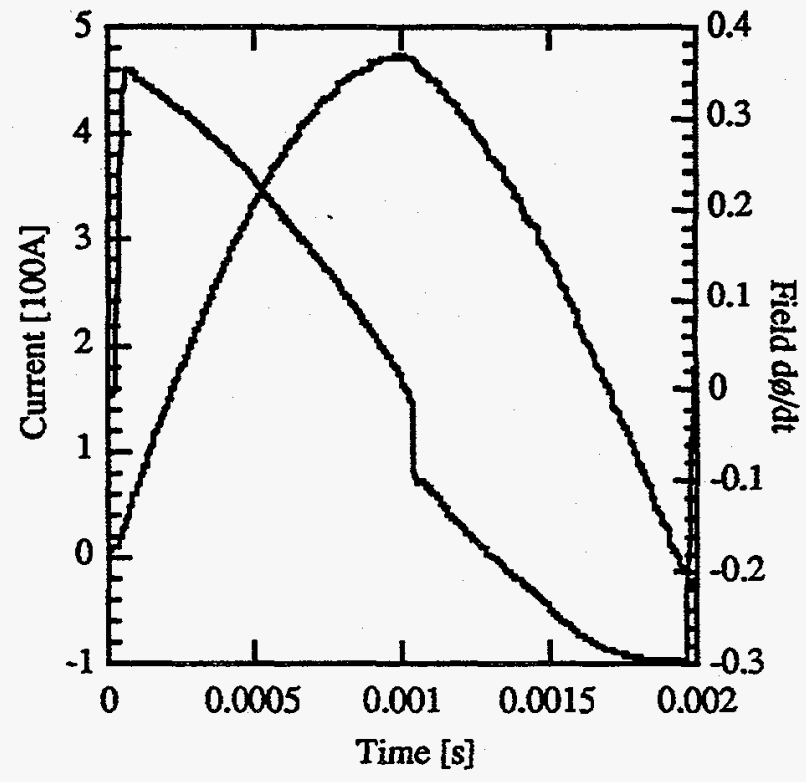

Figure 6. Magnet current and dø/dt waveforms.

\section{ACKNOWLEDGMENTS}

The authors extend their appreciation and gratitude to Scott Hewitt for his design skills during prototype construction and testing, and then we salute Victor Popov for his excellent testing support, construction skills and devotion to the project.

\section{REFERENCES}

[1] T. Fieguth et al, "PEP II Injection Transport Construction Status and Commissioning Plans," contributed to this conference.

[2] V. Nesterov and R. Cassel, "High Current Transistor Pulse Generator," proceedings of the 1991 IEEE Nuclear Science Symposium, pp. 1009-1011.

[3] T. Fieguth et al., ibid.

\section{DISCLAIMER}

This report was prepared as an account of work sponsored by an agency of the United States Government. Neither the United States Government nor any agency thereof, nor any of their employees, makes any warranty, express or implied, or assumes any legal liability or responsibility for the accuracy, completeness, or usefulness of any information, apparatus, product, or process disclosed, or represents that its use would not infringe privately owned rights. Reference herein to any specific commercial product, process, or service by trade name, trademark, manufacturer, or otherwise does not necessarily constitute or imply its endorsement, recommendation, or favoring by the United States Government or any agency thereof. The views and opinions of authors expressed herein do not necessarily state or reflect those of the United States Government or any agency thereof. 